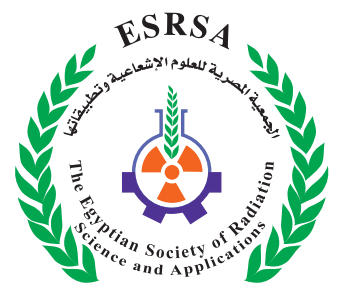

\title{
Dielectric Monitoring the Effect Green Copper Oxide Nanoparticles Incubation with Baker>s Yeast Cells Suspension
}

Rasha, S. Shams El Dine' ${ }^{1}$ Moustafa, M.H. ${ }^{1}$

Received: 16/06/2020

Accepted: 13/09/2020

DOI: $10.21608 /$ jntas.2020.32846.1022

E.mail:moustafa-hm@alexu.edu.eg

\section{ABSTRACT}

The current era of emerging nano-technology has immersed us in a sea of nanomaterials used in different fields of life. Copper oxide nanoparticles (CuONPs) are used in medical issues. Studies were conducted upon $\mathrm{CuONPs}$ cytotoxicity. The monitoring of cell viability was carried out by several methods mainly depends on cytolysis or membrane leakage. Many of these assays are invasive and the others are toxic. Electrical impedance measurement was a rational tool to investigate the biological materials by the mean of two electrodes. The current attempt aims at dielectric monitoring in form permittivity and conductivity spectrum of green (CuONPs) incubation effect with baker's yeast cells suspension. CuONPs are characterized by electron microscopy and Fourier transformer infrared (FTIR) spectroscopy was investigated under room condition.

\section{KEYWORDS}

Dielectric, Green

Synthesis, Copper

Oxide, Nanoparticles,

Yeast cells.

1. Biomedical physics Department, Medical research institute, Alexandria University, Alexandria, Egypt. 


\section{INTRODUCTION}

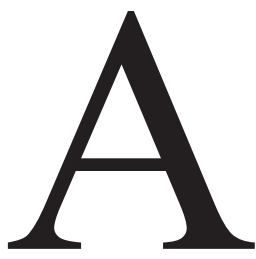

mong metal oxide, copper oxide nanoparticles (CuONPs) are used in electronic and optoelectronic industries as semiconductor, gas sensor, and solar cell thin films. CuoNPs are incorporated in marine antifouling paints and agricultural biocides that can become airborne and deposit in soil. Eventually CuO NPs can be released into the ecosystem from power stations, smelters, metal foundries, asphalt, inkjet printers and rubber tires and can undergo oxidation as active form (Jagathesan et al., 2018).

CuONPs also have a valuable trait in medical applications. CuONPs have antimicrobial activity against fungi and bacteria (Rossetto et al., 2014). They also are used as contrast agent for magnetic resonance imaging ultrasound dual imaging. Therefore, for appropriate utilization, the physiological behavior of CuONP should be fully understood to minimize the cytotoxic effects (Galván Márquez et al., 2018).

Retrospectively, several studies were conducted upon $\mathrm{CuONPs}$ cytotoxicity. The monitoring of cell viability was carried out by several methods mainly depends on cytolysis or membrane leakage (trypan blue), mitochondrial activity or caspase assay (Resazurin and Formosan), functional assay (hemoglobin assay), genomic and proteomics assay, and flow cytometry assay (Aslantürk, 2017).

Many of these assays are invasive and the others are toxic upon chemical kits like trypan blue, orange red viability test. The accuracy and reproducibility are limited. Moreover these methods are still expensive. A surge for new reliable and available monitoring methods was a challenge. During earlier decade, the electrical impedance measurement (EIM) was a rational tool to investigate the biological materials by the mean of two electrodes (Schwan,1963). (EIM) is noninvasive, real time methods for moni- toring impedance changes of living biological cells (Ogawa et al., 2020).

Several studies have reported a correlation between cell viability and impedance magnitude (Roohvand et al., 2017). Non-invasive physical methods were stepping up such as dielectric spectroscopy (DS), which provides simple, sensitive, real time, high throughput, and sterility maintenance for monitoring cell electrical (Ogawa et al., 2020). Dielectric spectroscopy mainly measures the dielectric permittivity of cell population that is the ability of cell to store electric charges over the scanning frequency using two electrodes (Roa, 2013).

The current attempt proposes to dielectric monitoring (permittivity and conductivity) of green copper oxide nanoparticles incubation effect with baker's yeast cells suspension under room condition.

\section{MATERIAL AND METHODS}

\section{Green Synthesis of Cu oxide nanoparticles (CuONPs)}

The synthesis procedure of nanoparticles was adopted from earlier work of (Awad $\boldsymbol{e t}$ al., 2013). A constant volume of the aqueous guava leaves extract of (about $10 \mathrm{ml}$ ) was mixed with Copper Sulphate $(\mathrm{CuSO} 4 \cdot 5 \mathrm{H} 2 \mathrm{O}) 5 \mathrm{ml}$ solution $(1 \mathrm{mM})$ with concomitant stirring at room temperature. The mixture was sonicated, then filtered to separate plant debris. Appearance of a dark color indicated the formation of $\mathrm{CuONP}$. Then, nanoparticles were precipitated by centrifugation at $13,000 \mathrm{rpm}$ for 10 minutes and stored at $-4{ }^{\circ} \mathrm{C}$ for further use.

\section{Electron Microscopy}

Surface and size morphology of yielded nanoparticles were monitored by using electron microscopy, transmission (JEOL1400 Plus, Japan) and scanning (JSM-5300, JEOL, Japan) electron microscopy. Sample preparation of nanoparticles was performed by drop coating method was on carbon coated cop- 
per grids under vacuum conditions. The average photographs, as shown in Figure 1. diameters of particles were deduced from captured

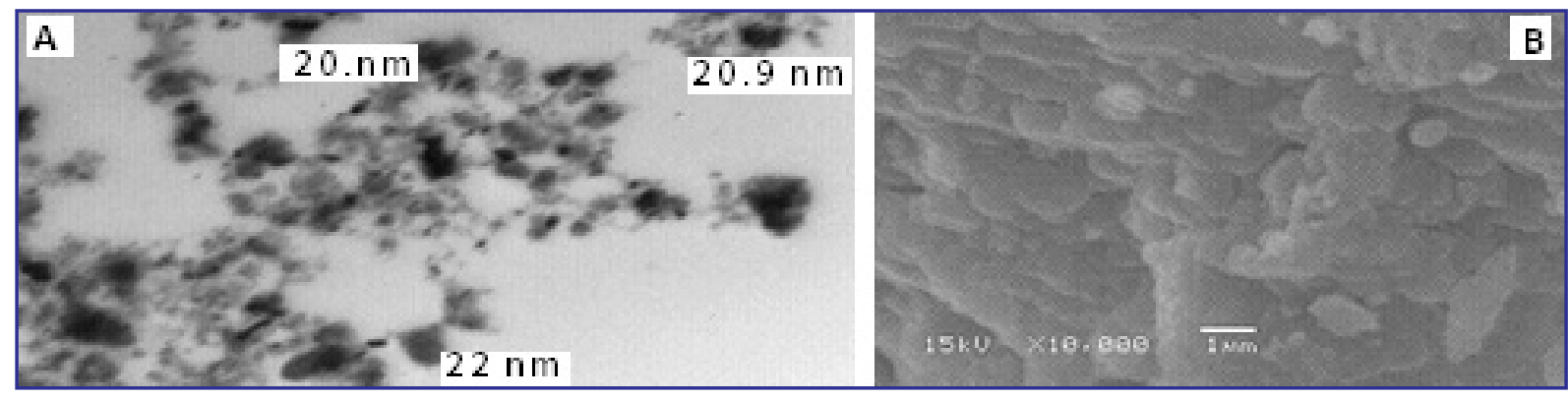

Fig. (1): Photographs of electron microscope, (A) transmission and (B) scanning, for the prepared CuONPs by the current green methods with corresponding screen deduced size.

\section{Fourier Transform Infrared Analysis (FT-IR)}

FT-IR (model: 8400s, Shimadzu corporation, Japan) spectroscopic technique was used to detect functional active groups bonding of the prepared nanoparticles via IR irradiation.

\section{Yeast cell preparation and CuNPs incubation}

Yeast cells are well studied. They are simple unicellular cells with unique features for ease of growth and genetic manipulation making it an exceptional host microbe and good candidates for medical application (Roohvand et al., 2017). Bakery dry yeast cells were purchased from local markets. Two grams yeast powder was added to $10 \mathrm{ml}$ distilled water pretreated with traces of table sugar (to maintain yeast cell viability) with concomitant stirring at $37^{\circ} \mathrm{C}$.

\section{Dielectric measurement}

Resistance and capacitance of yeast cells suspension was monitored at 5 and $50 \mathrm{kHz}$ frequencies via two square form silver electrodes connected to LCR meter (Hioki, 3532, LCR Hitester Japan, Physics Department, Faculty of Science, Damanhour University, Egypt) at room temperature $\left(24 \pm 0.1^{\circ} \mathrm{C}\right)$. Measurement cell was designed as two parallel cubic silver electrodes of $1 \times 1 \mathrm{~mm} 2$ area (A) and $5 \mathrm{~mm}$ apart (d). The permittivity $(\varepsilon)$ and conductivity $(\sigma)$ of yeast cells suspension were calculated from (Equation 1 and Equation 2) as a function of capacitance
(C) and conductance $(\mathrm{G})$ (reciprocal f resistance $\mathrm{R}$ ) at frequencies range of $1 \mathrm{kHz}-5 \mathrm{MHz}$.

$\varepsilon=C \cdot \frac{\mathrm{d}}{\mathrm{A}} \quad$ Equation 1

$\sigma=\frac{1}{R} \cdot \frac{\mathrm{d}}{\mathrm{A}} \quad$ Equation 2

\section{RESULTS}

\section{FT-IR peaks}

In the Figure 2, peaks at $1600 \mathrm{~cm}-1$ may concern the asymmetric and symmetric stretching vibration of COO- (10), which supports the presence of protein in the plant extract reducing agent for met-al precursors. The band at $1141 \mathrm{~cm}-1$ can be for the symmetric $\mathrm{C}-\mathrm{O}$ vibration associated with $\mathrm{C}-\mathrm{O}-\mathrm{SO} 3$ group. In addition, signals at $3900 \mathrm{~cm}-1$ (OH stretching), $2420 \mathrm{~cm}-1$ ( $\mathrm{CH}$ stretching) were noticed. The presence of $\mathrm{Cu}$ elements can be seen by two strong absorption bands at 620 and $770 \mathrm{~cm}-1$ (Sharma $e t$ al., 2017).

For all study cases a frequency dependence responses curves were noticed in Figure 3 Concerning permittivity, the trend begins with step-like increment followed by decrease till plateau stage. A contrary behavior occurred for the conductivity curves. At the current microwave frequency range, only $\beta$-dispersion of dipole relaxation may be mainly con- 
cerned during the permittivity response, $\alpha$-dispersion (ionic relaxation) could not occur as it is related to lower frequency range (Schwan, 1963).

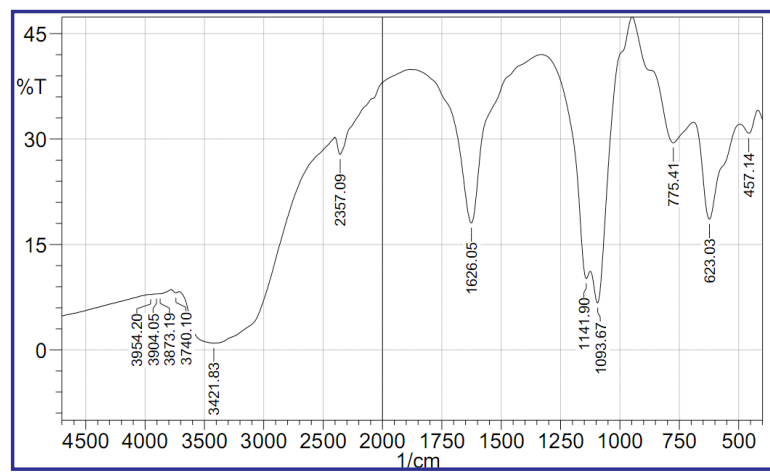

Fig. (2): Print-out of FT-IR shows values of transmission peaks of green $\mathrm{CuONP}$ powder.

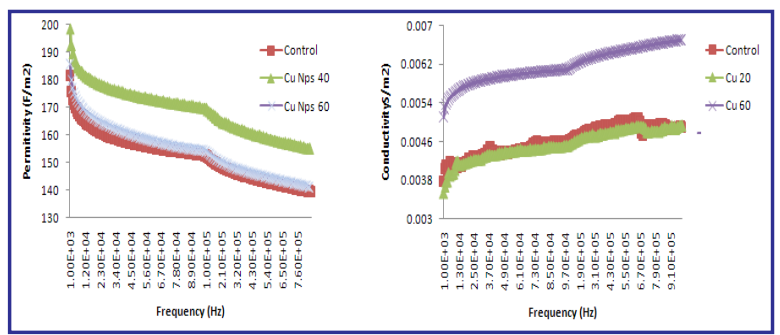

Fig. (3): Graphical representation of dielectric spectrum of yeast cell suspention at different $\mathrm{CuONPs}$ concentrations (20, 40, 60 ppm) (a) dielectric constant and (b) conductance.

As we noticed in the dielectric relaxation curve, higher permittivity at low frequency due to ionic conductivity and presence of free ions conductivity contributed to the dipole polarization (ionic and electronic), while at higher frequency the dipoles responses decrease which indicate normal dielectric behavior (Downey et al., 2014).

According to current results, the permittivity peak yeast cells decreases with increasing the concentration of (CuNPs). This observation may be due to the higher $\mathrm{Cu}$ ions presence in the sample. As the concentration of $\mathrm{Cu}$ ions increase, electrolytic conduction exists in the presence of a solvent and permittivity declines as frequency increase. The opposite behavior is noticed in conductivity spectrum. This behavior is typical characteristics of the polar dielectrics (Yao et al., 2019).

\section{CONCLUSION}

In brief, the present work employed the electrical characteristics of living yeast cells (electrical permittivity and conductivity) to monitor to cell integrity and viability under the influence of copper oxide nanoparticles incubation. The dielectric spectrum as impedance spectroscopy, showed sensitive, fast, affordable, real time and screening to cell ionic change under the influence of external effect. The opposite behavior is noticed in conductivity spectrum. This behavior is typical characteristics of the polar dielectrics

\section{ACKNOWLEDGEMENT}

Grateful acknowledgment is expressed for the valuable contributions of Dr. Doaa Talhaa, Pharos University, from Medical equipment Department, for his technical and laboratory assistance to bring the work to light.

\section{REFERENCES}

- Aslantürk, Ö. S. (2017): In Vitro Cytotoxicity and Cell Viability Assays: Principles, Advantages, and Disadvantages. In: Marcelo, L.L., and Sonia, S., editors. Genotoxicity - A Predictable Risk to Our Actual World, London, UK: Intech Open.

- Awwad, A.M.; Salem, N.M. and Abdeen, A.O. (2013): Green synthesis of silver nanoparticles using carob leaf extract and its antibacterial activity. Int. $J$. Ind. Chem., 4: 29.

- Downey, B.; Graham, L.; Breit, J. and Glutting, N. (2014): A novel approach for using dielectric spectroscopy to predict viable cell volume (VCV) in early process development. Biotechnol. Prog., 30(2): 479.

- Galván Márquez, I.; Ghiyasvand, M.; Massarsky, A.; Babu, M.; Samanfar, B.; Omidi, K.; Moon, T.; Smith, M. and Golshani, A. (2018): Zinc oxide and silver nanoparticles toxicity in the baker's yeast, Saccharomyces cerevisiae. PLoS One, 13(3): p.0193111.

- Jagathesan, G. and Rajiv, P. (2018): Biosynthesis 
and characterization of iron oxide nanoparticles using Eichhornia crassipes leaf extract and assessing their antibacterial activity. Biocatal. Agric. Biotechnol., 13: 90.

- Ogawa, R.; Baidillah, M.; Akita, S. and Takei, M. (2020): Investigation of physiological swelling on conductivity distribution in lower leg subcutaneous tissue by electrical impedance tomography. J. Electr. Bioimpedance, 11(1):19.

- Roa Romero, L. (2013): 2 n.d. Mediterranean Conference on Medical And Biological Engineering And Computing.

- Roohvand, F.; Shokri, M.; Abdollahpour-Alitappeh, M. and Ehsani, P. (2017): Biomedical applications of yeast- a patent view, part one: yeasts as workhorses for the production of therapeutics and vaccines. Expert Opin. Ther. Pat., 27(8): 929.

- Rossetto, A.; Melegari, S.; Ouriques, L. and Matias, W., (2014): Comparative evaluation of acute and chronic toxicities of $\mathrm{CuO}$ nanoparticles and bulk using Daphnia magna and Vibrio fischeri. Sci. Total Environ., 490: 807.
- Schwan, H. (1963): Electric Characteristics of Tissues. Biophysik., 1(3): 198

- Sharma, S. and Uttam, K., (2017): Rapid analyses of stress of copper oxide nanoparticles on wheat plants at an early stage by laser induced fluorescence and attenuated total reflectance Fourier transform infrared spectroscopy. Vib. Spectrosc., 92: 135-150.

- Wongrakpanich, A.; Mudunkotuwa, I.; Geary, S.; Morris, A.; Mapuskar, K.; Spitz, D.; Grassian, V. and Salem, A. (2016): Size-dependent cytotoxicity of copper oxide nanoparticles in lung epithelial cells. Environ. Sci. (Nano), 3(2): 365.

- Yao, J.; Liu, X.; Xu, Z.; Zhao, T.; Chen, B.; Wu, H. (2019): Electrical Impedance Tomography for Biological Cell Sensing with Microfluidic Device. Mech. Eng. J, 55(2): 1. 
